\title{
Hepatitis sifilítica: una patología "poco frecuente"
}

\author{
A. De Miguel Gómez, J .R. Benedicto Sánchez \\ Médicos de Familia \\ Centro de Salud San Antón. Cartagena. Murcia.
}

Syphilitic hepatitis: “a non-frecuent” pathology

\section{RESUMEN}

La Atención Primaria (AP) tiene un importante papel en diversas patologías, que por su baja inci dencia no tenemos presente y una vez diagnosticadas, derivamos a Atención Especializada, en ocasiones por no tener claro su manejo. Se presenta el caso de un varón de 57 años, homosexual, con múltiples con tactos de riesgo, que debuta con una balanitis segui da de un cuadro de malestar general, febrícula, icte ricia, coluria y hepatomegalia. El estudio realizado nos confirma un cuadro de hepatitis aguda de "causa incierta”, toda vez descartada etiología viral y tóxica. En el desarrollo del caso clínico veremos cómo se lle ga al diagnóstico de hepatitis sifilítica y su curación completa. El manejo siempre se ha realizado desde $A P$, manteniendo la atención integral al individuo y gracias al trabajo en equipo multidisciplinario.

Palabras clave: Hepatitis sifilítica. Atención Primaria.

\begin{abstract}
Primary Care has an important role dealing with several pathologies. However, due to its little effect and sometimes an unknown control of them we resort to Specialized Care once they are diagnosed. A 57 year old man, homosexual, involved in many risky sexual intercourse, appears with a balanitis followed by general discomfort, fever, jaundice, coluria and hepatomegaly. The study confirms us an "Acute He patitis" of "unknown reason", ruling out viral etio logy and toxic. In the development of this clinic case we see how it develops to Syphilitic Hepatitis and its complete cure. The managemente of the pathology has always been made from Primary Care maintai ning a total attention to the patient and thanks to a multidisciplinary group.
\end{abstract}

Key words: Syphilitic Hepatitis. Primary Health Care.

sis, de la exploración física, y sobre todo los antecedentes personales, llegamos al diagnóstico de sospecha, descartando siempre otras causas. La remisión completa nos dió el diagnóstico de certeza.

\section{OBSERVACIÓN CLÍNICA}

Varón de 57 años que no refiere ingesta de medicamentos hepatotóxicos. Consumo de alcohol moderado (<20 g/día). Múltiples contactos sexuales no

Aceptación: 27-11-01 
protegidos, con distintas parejas. Consulta por probable balanitis, con bordes del prepucio engrosados que impiden valorar glande, prescribiéndose un antimicótico tópico. Dos semanas después, comienza con un cuadro de malestar general, astenia y febrícula. A los 3 días del inicio de esta sintomatología, presenta fiebre elevada durante 2 días y comienza con ictericia y coluria. A la exploración física destaca hepatomegalia indolora de $2-3 \mathrm{~cm}$ que se confirma por pruebas de imagen (ecogenicidad aumentada pero homogénea, sin otras lesiones valorables). El hemograma muestra $\mathrm{Hb} 11,6 \mathrm{~g} / \mathrm{dl}$, Hto $35 \%$, leucocitos 5.890/ $\mu$ l con fórmula normal. Coagulación normal. La bioquímica mostró GOT 187 UI/L, GPT 231 UI/L, Gamma-GT 849 UI/L, FA 1132 UI/L, es decir, un patrón colestásico. El resto de los parámetros dentro de los límites normales. Se solicitan marcadores de hepatitis vírica siendo negativos.

Una semana más tarde, vuelve a consulta por aparición de lesiones eritematosas en ambas palmas y antebrazos, pruriginosas, de 3 días de evolución. Ante la sospecha clínica y las prácticas de riesgo se solicita serología de sífilis que confirma el dignóstico de LUES con títulos de RPR 1/256, TPHA 1/1280 y FTA-ABS ++++. VIH-.

Se pauta tratamiento con Penicilina G Benzatina 2.400.000 UI y la mejoría clínica es espectacular, así como la normalización de las transaminasas, cuyos valores a los 15 días de instaurado el tratamiento eran GOT 21 UI/L, GPT 31 UI/L. La FA también era normal (159 UI/L), aunque aún persistía Gamma GT 75 UI/L (trabaja en un bar y dudamos de consumo de alcohol). La ecografía abdominal demostró desaparición de la hepatomegalia. El RPR había descendido hasta títulos de 1/128, lo que indicaba evolución a la curación.

Por último, se solicitó nueva serología viral a los 3 meses de inciciado el cuadro, para descartar "periodo ventana".

Ante la mejoría clínica, analítica y ecográfica de la hepatitis, sin causa viral, medicamentosa o tóxica que justifique el cuadro y evolucionando hacia la curación tras tratamiento con Penicilina G Benzatina, se confirma el diagnóstico de hepatitis sifilítica.

\section{DISCUSIÓN}

La importancia de este caso reside en la baja incidencia del mismo, pues no son frecuentes las manifestaciones hepáticas en la sífilis, menos aún como síntomas iniciales y excepcionales las que cursan con un patrón de colestasis. La hepatitis sifilítica se distingue por fosfatasa alcalina sérica elevada, histología inespecífica distinta a la de la hepatitis viral y que consiste en inflamación moderada por linfocitos y leucocitos PMN, discreta lesión hepatocelular y ausencia de colestasis ${ }^{1}$. Consideramos necesario un cierto grado de sospecha clínica en los casos de he- patitis aguda de causa incierta, pues la sífilis podría ser considerada como posible causa, siempre en ausencia de otros signos y hallazgos analíticos que orienten a otras etiologías ${ }^{2}$.

Algunos autores consideran imprescindible para el diagnóstico de hepatitis sifilítica los hallazgos microscópicos en la biopsia hepática ${ }^{3}$, además de las características clínicas, psicológicas y analíticas; sin embargo, encontramos apoyo en la literatura, pues diversos estudios han demostrado que no siempre es posible la visualización de treponemas en el hígado. Su presencia es criterio diagnóstico, pero la no visualización no lo excluye ${ }^{4}$.

El patrón colestásico en la hepatitis sifilítica es raro, siendo más importante el grado de colestasis que el de histolisis (ésta suele ser moderada). Las manifestaciones hepáticas agudas en la sífilis son más frecuentes en personas con prácticas homosexuales ${ }^{6}$, además de facilitarse la transmisión de la infección por VHB pudiendo enmascarar la verdadera etiología de la hepatitis y atribuirla a causa viral, en nuestro caso descartada por serología ${ }^{7}$.

La hepatitis por tóxicos (metales pesados, paracetamol, citostáticos,...) en principio queda descartada por el patrón colestásico, ya que en estos casos suele ser de citolisis intensa, además de que algunos alteran la función renal ${ }^{8}$, siempre normal en nuestro caso.

No es infrecuente la asociación de hepatitis aguda sifilítica con síndrome nefrótico ${ }^{9}$, aunque en ningún momento se presentó en este paciente. También se puede asociar a artritis, intolerancia a los hidratos de carbono,... ${ }^{10}$.

En nuestro repaso por la literatura publicada al respecto en los últimos 20 años, hemos comprobado un punto común como criterio diagnóstico: la remisión de la clínica, normalización de las transaminasas y negativización de la serología tras el tratamiento con Penicilina G Benzatina 2,4 millones $\mathrm{UI}^{11}$, como ocurrió en nuestro caso.

Especialmente importante se concluye de lo expuesto el interés de su diagnóstico, pues se trata de una patología subsidiaria de curación con tratamiento adecuado. Queremos hacer hincapié en que todo el proceso evolutivo puede ser llevado desde Atención Primaria, como así ha sido en nuestra experiencia.

\section{AGRADECIMIENTOS}

Quisieramos expresar nuestro agradecimiento a Dña. Marisa Pardo Pastoris y a Dña. Susana Martínez Otón por su colaboración en este artículo.

\section{CORRESPONDENCIA:}

José Ramón Benedicto Sánchez

C/ Pintor Balaca, 31, $8^{\circ}$ B. Edf. Alejandría.

30203 Cartagena. Murcia

Telf.: 617773249

e-mail: josebenedicto@eresmas.com 


\section{Bibliografía}

1. Lukehart SA, Holmes KK. Sifilis. En: Harrison. Principios de Medicina Interna. 13 ${ }^{\mathrm{a}}$ ed. Madrid: Ed. Mc Graw-Hill Interamericana de España, 1994. p. 846-58.

2. Gschawantler M, Gulz W, Schrutka-Kolbl C, Kogelbauer G, Schober G, Bibus B, et al. Hepatitis aguda como síntoma inicial de la hepatitis secundaria. Dtsch Med Wochenschr 1996; 47: 1457-61.

3. Balikocioglu A, Quaidoo E, Vulentin JC, Trotman BW. Hepatitis y glomerulonefritis en sífilis secundaria. J Assoc Acad Minor Phys 1991; 2: 72-5.

4. Roge G, Husson JM, Biclet P, Camilleri JP, Amat D, Roge F, et al. ¿Existe la afectación hepática en la sífilis secundaria? A propósito de dos casos. Nov Presse Med 1979; 41: 3335-8.

5. Guillaume JC, Lejonc JL, Touraine R. Hepatitis y sífilis secundaria. Annual Dermatologic Venereologic 1981; 3: 253-6.

6. Mulder AH. Sífilis Primaria con síntomas de hepatitis. Ned
Tijdschr Geneeskd 1980; 24: 973-5.

7. Bratos MA, Eiros JM, Orduna A, Cuervo M, Ortiz de Lejarazu R, Almaraz A, et al. Influencia de la sífilis en la transmisión de la Hepatitis B en un grupo de prostitutas. Sexual Transmision Disease 1993; 5: 257-61.

8. Ortiz Marín M, Ramos Rincón JM, Alberca F, Arribas Ros JP. Hepatitis colestásica probablemente inducida por ticlopidina en mujer con hipotiroidismo. [Carta] MEDIFAM 2001; 11: 106-8.

9. Tang AL, Thin RN, Croft DN. Síndrome nefrótico y hepatitis en sífilis temprana. Postgrad Med J 1989; 65: 14-5.

10. Williams WC, Marion GS. Sífilis secundaria que cursa con artritis, hepatitis e intolerancia a los hidratos de carbono. J Fam Prac 1987; 25: 509-11.

11. Duffaut M, Gailemin C, Arlet P, Botreau Y, Le Tallec Y. Hepatitis B y sífilis secundaria. A propósito de 3 casos. Nov Presse Med 1980; 9: 2845-6. 